NASA Technical Memorandum 100892

\title{
Auger Analysis of a Fiber/Matrix Interface in a Ceramic Matrix Composite
}

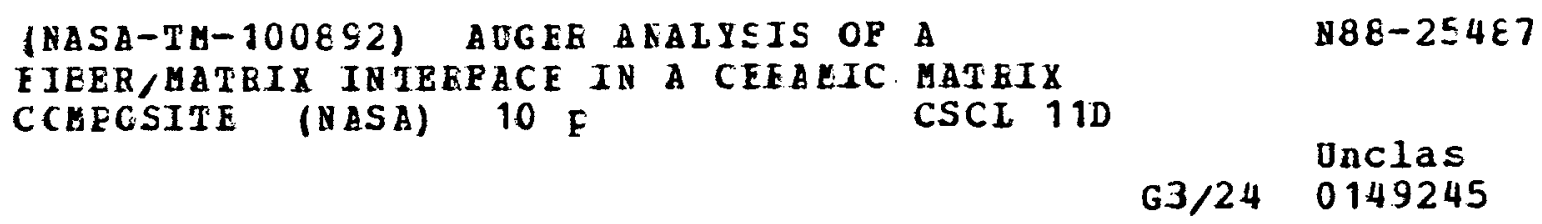

Frank S. Honecy

Case Western Reserve University

Cleveland, Ohio

and

Steven V. Pepper

Lewis Research Center

Cleveland, Ohio

Prepared for the

Spring Meeting of the Materials Research Society

Reno, Nevada, April 4-9, 1988 


\title{
AUGER ANALYSIS OF A FIBER/MATRIX INTERFACE IN A
}

\author{
CERAMIC MATRIX COMPOSITE \\ Frank S. Honecy \\ Case Western Reserve University \\ Department of Mechanical and Aerospace Engineering \\ Cleveland, Ohio 44106 \\ and \\ Stephen V. Pepper \\ National Aeronautics and Space Administration \\ Lewis Research Center \\ Cleveland, Ohio 44135
}

\begin{abstract}
SUMMARY
Auger electron spectroscopy (AES) with depth profiling was used to characterize the fiber/matrix. Interface of a SiC fiber, reaction bonded $\mathrm{Si}_{3} \mathrm{~N}_{4}$ matrix composite. Depth profiles of the "as received" double coated fiber revealed concentration oscillations which disappeared after annealing the fiber in the environment used to fabricate the composite. After the composite was fractured, the Auger depth profiles indicated that fallure occurred in neither the $\beta-S i C$ fiber body nor in the $\mathrm{Si}_{3} \mathrm{~N}_{4}$ matrix but, concurrently, at the fiber coating/matrix interface and within the fiber coating itself.
\end{abstract}

\section{INTRODUCTION}

Fiber reinforced composites have long been recognized as a way of combining the desirable properties of dissimilar materials to achieve materials which, as a result of the combination, have properties not readily achievable otherwlse. One such composite, currently being studied at NASA for high temperature use, is silicon carbide flber reinforced, reaction bonded sllicon nitride (SIC/RBSN) (ref. 1). The RBSN matrix material exhibits high temperature strength, low density, and other desirable properties, but exhibits brittle fracture behavior. The SiC fiber contributes to ductility by interrupting cracks and by taking some of the strain in the composite. The properties of the composite material depend not only on the individual components but on the nature of the bond between the partners and on the chemical reactions that occur during processing.

The aim of this study is to provide information on the chemical composition of the SIC fiber surface coating both before and after exposure to the composite processing environment, the chemical composition of the fiber-matrix interfacial region in the processed material, and to determine the locus of fallure in a composite fractured along the fiber direction. The experimental approach to these topics is to use Auger electron spectroscopy with depth

*NASA Resident Research Associate. 
profiling to obtain elemental and chemical information as a function of depth below the surface of a free-standing fiber, and also for a fiber embedded in a matrix exposed by fracture and the corresponding trough left in the mating matrix. The analysis of the free-standing fiber provides a bas is for interpreting the analysis of the fibers embedded in the composite matrix.

\section{EXPERIMENTAL}

The composite used in this study consists of double-coated $142 \mu \mathrm{m}$ diameter $\beta$-SiC fibers embedded unidirectionally in a RBSN matrix. The $\sim 4 \mu \mathrm{m}$ thick double coating consists of two carbon-rich regions separated by a silicon-rich region. The volume fraction of the fibers is approximately 35 percent. The matrix material is approximately 70 percent of theoretical density. A more complete description of the composite is contalned elsewhere (ref. 1). The composite was fractured outside the analytical chamber by pulling it apart perpendicular to the fiber axes, exposing the fibers and matching troughs.

Auger spectroscopy was performed using a Perkin-Elmer Physical Electronics Division Model 545 Scanning Auger Microprobe (SAM) with an analytical spot size of approximately $5 \mathrm{\mu m}$. Auger $d N(E) / d E$ peaks for $5 i$ at $92 \mathrm{eV}, \mathrm{C}$ at $272 \mathrm{eV}$, $\mathrm{N}$ at $382 \mathrm{eV}$, and 0 at $512 \mathrm{eV}$ were monitored during Art bombardment with a $3 \mathrm{M}$ Minibeam ion gun. Composite fracture surface depth profiles for corresponding fiber and trough areas were taken, where possible. The insulating properties of the pure $\mathrm{Si}_{3} \mathrm{~N}_{4}$ matrix material causes uncontrollable charging under our electron beam, rendering AES of it impossible.

Atomic concentrations were calculated using

$$
c_{x}=\frac{I_{x} / S_{x}}{\sum_{i}^{M} I_{i} / S_{i}}
$$

Where $C_{x}$ is the atomic concentration of element $x, M$ is the number of atomic species present, If denotes $d N(E) / d E$ intensities, and $S_{i}$ denotes relative sensitivities for the pure elements referenced to some standard. Sputter depths were calculated using

$$
d_{n}=d_{n-1} \cdot\left(t_{n}-t_{n-1}\right) \cdot \sum_{i}^{M} \sigma_{i} \cdot c_{i} \cdot
$$

Where $d$ is depth, $t$ is time, and $\sigma$ is the sputter rate for a pure species. Sources of $\sigma$ and $S$ values include system calibration using standards and the literature (refs. 2 to 4 ).

\section{RESULTS}

\section{Fiber}

Figure $1(a)$ is a typical depth profile of a single "as received" fiber. A Si-rich region is found between the two C-rich regions of the coating. Neither 
$O$ nor $N$ is observed in either the fiber or the coating. The $C$ and Si concentrations have been callibrated from Auger spectra of lon bombarded single crystal $\beta-S i C$. Using this calibration, stoichiometric SiC in the fiber is identified. Across the top of figure l(a) are the Auger lines whose shapes are indications of the chemical state of the elements. The shape of the $C$ peak at $d=1.4 \mu \mathrm{m}$ is typical of amorphous carbon, while the $C$ peak above the area labeled bulk $B-S i C$ is typical of $\beta-S I C$ (refs. 3 to 5 ). In between these two extremes the $C$ peaks show characteristics of mixtures of both chemical states. These peak shapes are also typical across all of the profiles. Oscillations. in concentration are observed beginning at a depth of approximately $1.5 \mu \mathrm{m}$. These oscillations were apparent in the raw $\mathrm{dN}(E) / \mathrm{dE}$ versus time data before concentration and depth calculations were made. Similar oscillations appeared in each of several depth proflles done on the "as recelved" fibers taken from two different lots. The oscillations do not display periodicity nor do they appear to be a function of concentration or depth -- except that they are not evident in the top $1.0 \mu \mathrm{m}$ of the coating. The oscillations of $S i$ and $C$ are physical; i.e., a decrease in $C$ is accompanied by an increase in $S i$ and vicé versa. As seen in flgure $1(b)$, depth proflles of fibers that were annealed in conditions identical to those which the matrix preforms receive in nitriding ( 1 atm $\mathrm{N}_{2}$, $1200^{\circ} \mathrm{C}, 40 \mathrm{hr}$ ) do not contain these oscillations. The interface widths of these annealed fibers are also considerably narrower than those of the "as recelved" fibers. The width of the inner carbon coating/ $\beta$-Sic interface decreases from $\sim 2.0$ to $\sim 0.5 \mu \mathrm{m}$. Note also, in the figure $1(\mathrm{~b})$ inset, the presence of $O$ and $N$ some distance into the coating and the depletion of Si over this same distance.

\section{Composite}

Both the flbers and the mating troughs of the fracture surface were analyzed. None of the chargeable $\mathrm{Si}_{3} \mathrm{~N}_{4}$ matrix material was found on any fiber surface. None of the depth profiles obtained from the embedded fibers exhibited the full range of features found in the coatings of either the "asreceived" or the annealed free-standing fibers. Instead, their profiles, shown in figure 2, fall into three categorles. Of a total of twelve depth profiles into three different fracture surfaces, six are similar to figure $2(a)$, three are similar to figure $2(b)$, and three are similar to figure $2(c)$. No 0 or $N$ is present in either of the (a) or (b) type profiles. Figure $2(c)$ is representative of relatively shallow depth profiles that were taken before the SAM system was set up to do the deep profiling that allowed calculation of the surface position relative to the inner carbon coating/ $\beta-S i C$ interface. These were the only profiles showing $N$; but, the se could not be reproduced once deeper proflles became possible. The only difference within each of the three different types of profiles is a $\sim 0.2 \mu \mathrm{m}$ variation in the distance from the fracture surface to the inner carbon coating/ $\beta-S 1 C$ interface.

Analysis of the troughs generally revealed only a thin, easily removed layer of adventitious carbon on the chargeable $\mathrm{Si}_{3} \mathrm{~N}_{4}$ matrix material. One proflle, however, showed $\sim 200 \AA$ of $C$ on the matrix. The profile of the fiber mate to this one trough is of the figure $2(a)$ type. No substantial fraction of the coating could be identifled in any trough. 


\section{DISCUSSION}

AES analysis of this system is difficult because the insulating nature of $\mathrm{SI}_{3} \mathrm{~N}_{4}$ leads to uncontrollable surface charging. Fiber AES is even compromised when the fiber is in the matrix due to charging of the adjacent matrix by $e^{-}$ spillover. However, a successful combination of $\mathrm{e}^{-}$current, $\mathrm{Ar}^{+}$current, and grazing incidence was found such that AES has proven to be a viable method for fiber analysis of this particular ceramic/ceramic composite. Although we have not been able to examine the RBSN matrix directly, if any measurable $C$ is present. AES is possible. The usual caveats that apply regarding the accuracy of concentration and depth calculations are also emphasized by this charging phenomenon. In spite of this, the calculated concentrations and distances do give reasonable agreement with those obtained from other sources (ref. 6 ).

The Auger peak shapes present at the top of figure 1(a) are representative of those found in the fiber whether the fiber was isolated or in the composite. They were used to confirm the physical interpretation of Auger peak height ratios in terms of the chemical nature of the material. In general the shape of the $\mathrm{C}$ and $\mathrm{SI}$ peaks (and the $\mathrm{N}$ and $\mathrm{O}$ peaks when found) followed what would be expected from their relative concentrations. On those embedded fiber surfaces where $N$ was found ( $f i g .2(c)$ ), there was some $S i$ peak splitting that is evidence for Si presence in more than one chemical state; unfortunately the $S i$ peak resolution was not good enough to allow more to be said about these chemtcal states.

\section{Fibers}

The analyses of the isolated fibers demonstrate that our Auger depth profiling technique can, in fact, provide elemental and chemical information as deep as $4 \mu \mathrm{m}$. These profiles can thus serve as a basis for interpreting the profiles of the flber surfaces embedded in the composite.

These isolated fiber profiles are interesting in themselves, however. Comparison of these profiles before and after annealing indicates that considerable diffusion takes place during the annealing process, with the features within the profile sharpening up considerably. By extension, this same behavior would be expected to occur in the fiber during composite nitriding.

A comparison of figure $1(a)$ to $(b)$ indicates an apparent $\sim 0.5 \mu \mathrm{m}$ thinning in the coating after anneal and significant 0 and $N$ diffusion into the coating (fig. 1(b) inset). Some Si depletion in the near surface region of the annealed fiber is consistent with the active oxidation that $S i$ is known to undergo at the small partial pressures of oxygen present as an impurity in the $\mathrm{N}_{2}$ used during the anneal (ref. 7). Whether the thickness difference noted above is due to sio evaporation during anneal or to a variation in the original coating thickness should be resolvable with further study.

The oscillations in the $S i$ and $C$ concentrations present in the "as received" fibers ( $f 1 g$. I(a)) are not understood at this time. They are evidently introduced during the manufacturing process and are removed by mass transport during subsequent annealing. 
Since no coating material was found in the matrix troughs, which remained geometrically identifiable, and no matrix material was found on the fiber surfaces, a conclusion is that fallure is occurring at the coating/matrix interface. On the other hand, fallure is occurring in the coating between the fiber and the matrix. A comparison of figure $1(b)$ with figure $2(a)$ and (b) illustrates this: fallure occurs at I and II in figure $l(b)$ for the cases of figure $2(a)$ and (b) respectively. The overall conclusion is that failure is occurring concurrently at the coating/matrix interface and within the coating. It is therefore shown here that the coating is in fact doing what it was designed to do -- provide the weak link between the fiber and the matrix.

There are, however, two issues to be resolved. First, the material in the region between the two fracture surfaces outlined above must be accounted for. That it may have been reacted with during the reaction bonding has to be considered. However. SEM of transverse polished sections of the composite indicate that this region of the coating survives reaction bonding. Further work is required to locate this missing region. Second, the profiles in figure $2(\mathrm{c})$ imply that fracture may be closer to the matrix/coating interface in these cases. This is still a case of coating fallure. However, these profiles, obtained in the early part of the work, could not be reproduced after the ability to profile down to the $\beta-S i C$ was developed. Further work is needed to see if this fallure mode is a significant occurrence.

\section{CONCLUSIONS}

1. The technique. - (a) Deep profiles $(\sim 4 \mu \mathrm{m})$ into the fibers yield useful chemical information with good depth resolution; (b) AES is possible on the fracture surface fibers in spite of the insulating properties of $\mathrm{Si}_{3} \mathrm{~N}_{4}$.

2. The fibers. - (a) The composition of the flber coating confirms the manufacturer's claims; (b) the composition of the fiber coating contains oscillations in $S i$ and $C$ concentration as the coating/ $\beta-S i C$ boundary is approached; (c) after annealing, these osclllations disappear as a result of mass transport, which also results in sharper interfaces.

3. The composite. - (a) The full fiber coating does not adhere to any surface exposed during fracture of the composite; (b) fracture is occurring in neither the $\mathrm{Si}_{3} \mathrm{~N}_{4}$ matrix nor the $\beta$-SiC fiber but in the region between the two; (c) fracture appears to occur concurrently within the coating and at the coating/matrix interface; but, further work is necessary to more fully understand the fracture process.

\section{REFERENCES}

1. R.T. Bhatt, in Talloring Multi-Phase and Composite Ceramics. MRS Vol. 20, R.E. Tressler, G.L. Messing, C.G. Pantano, and R.E. Newnham, eds., pp. 675-686, Plenum Press, NY (1986).

2. L.I. Maissel, in Handbook of Thin Film Technology, L.I. Maissel, and R. Glang, eds., p. 4-40, McGraw-Hill, NY (1970). 
3. G.E. McGuire, Auger Electron Spectroscopy Reference Manual, Plenum Press, NY (1979).

4. P.W. Palmberg, G.E. Riach, R.E. Weber, and N.C. Macdonald, Handbook of Auger Electron Spectroscopy. Physical Electronics Industries Inc., Edina, MN (1972).

5. D. Briggs, and J.C. Riviere, in Practical Surface Analysis by Auger and X-Ray Photoelectron Spectroscopy, D. Briggs, and M.P. Seah, eds., pp. 97104, Wiley \& Sons, NY (1983).

6. R.T. Bhatt, private communication, NASA Lewis Research Center, Cleveland, $\mathrm{OH}$ (1988).

7. C. Wagner, J. App 1. Phys., 29, 1295 (1958): Corros. Soc., $\underline{5}, 751$ (1965).

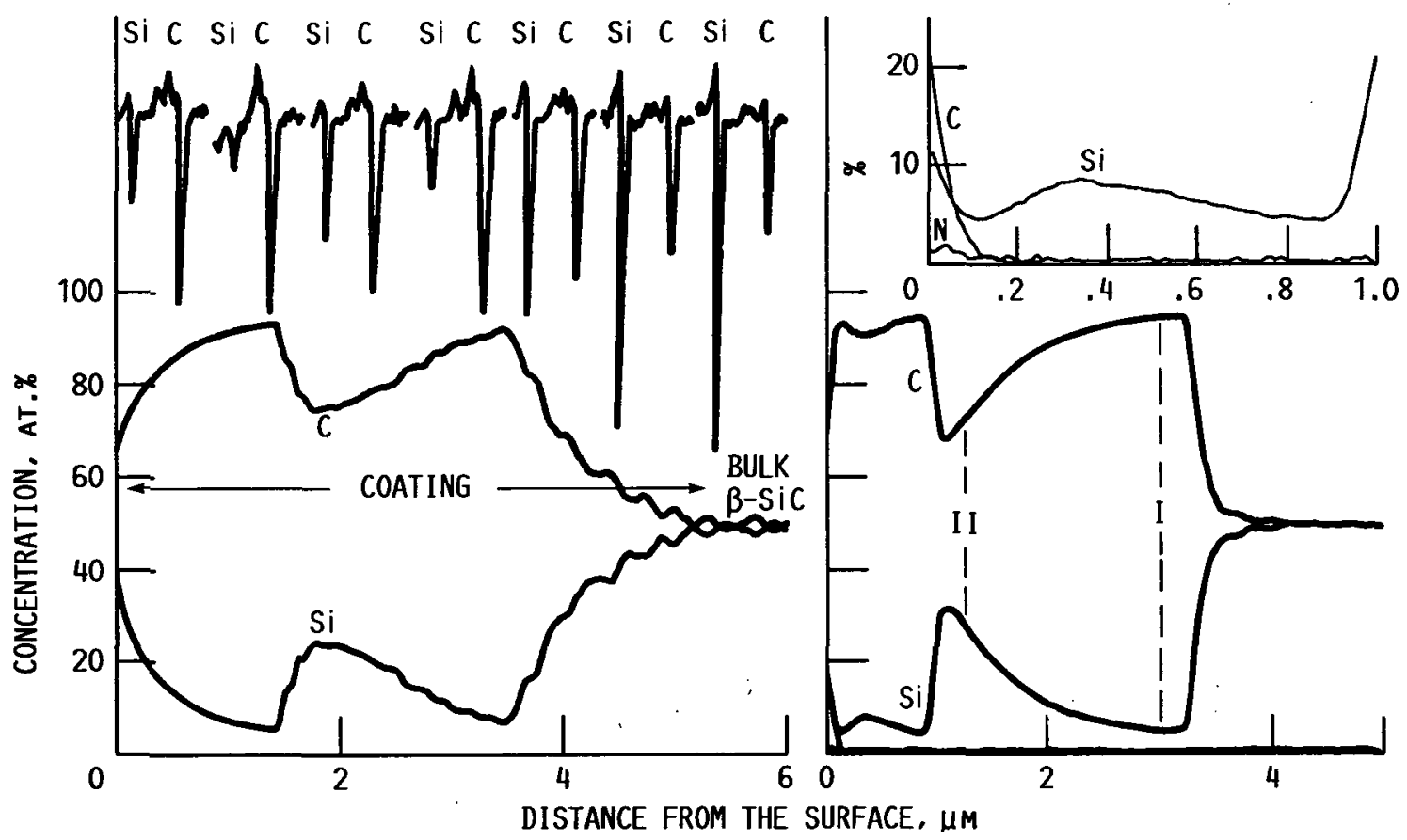

(a) "AS-RECEIVED" FIBER WITH CHARACTERISTIC (b) FIBER AFTER ANNEAL ( 1 ATM $\mathrm{N}_{2}$ AT Si AND C AUGER dN(E)/dE PEAK SHAPES CORRESPONDING TO CONCENTRATION. $1200{ }^{\circ} \mathrm{C}$ FOR 40 HR) WITH INSET SHOWING NEAR SURFACE DETAIL.

FIGURE 1. - CONCENTRATION AS A FUNCTION OF DISTANCE FROM THE SURFACE INTO A FREESTANDING FIBER. 

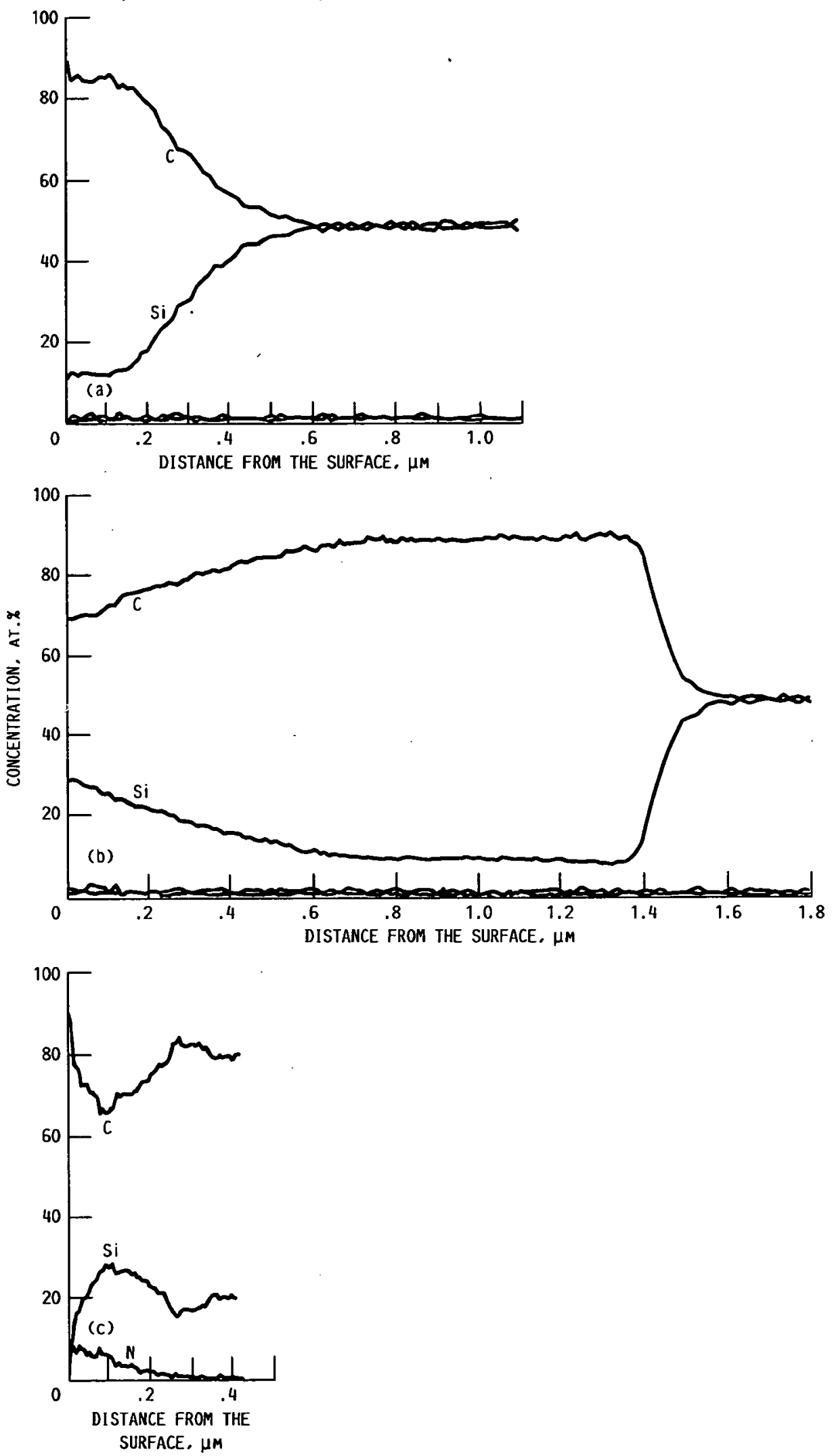

FIGURE 2 . - CONCENTRATION AS A FUNCTION OF DISTANCE FROM THE SURFACE FOR THE FIBER IN THE RBSN MATRIX - CHARACTERISTIC DEPTH PROFILES INTO THE THREE DIFFERENT TYPES OF FRACTURE SURFACES FOUND. (THE LINES AT - 2\% CONCENTRATION IN (a) AND (b) ARE THE 0 AND $N$ DEPTH PROFILES AT THE SPECTRUM NOISE LEVEL. NEITHER 0 NOR N IS PRESENT IN THESE PROFILES.) 


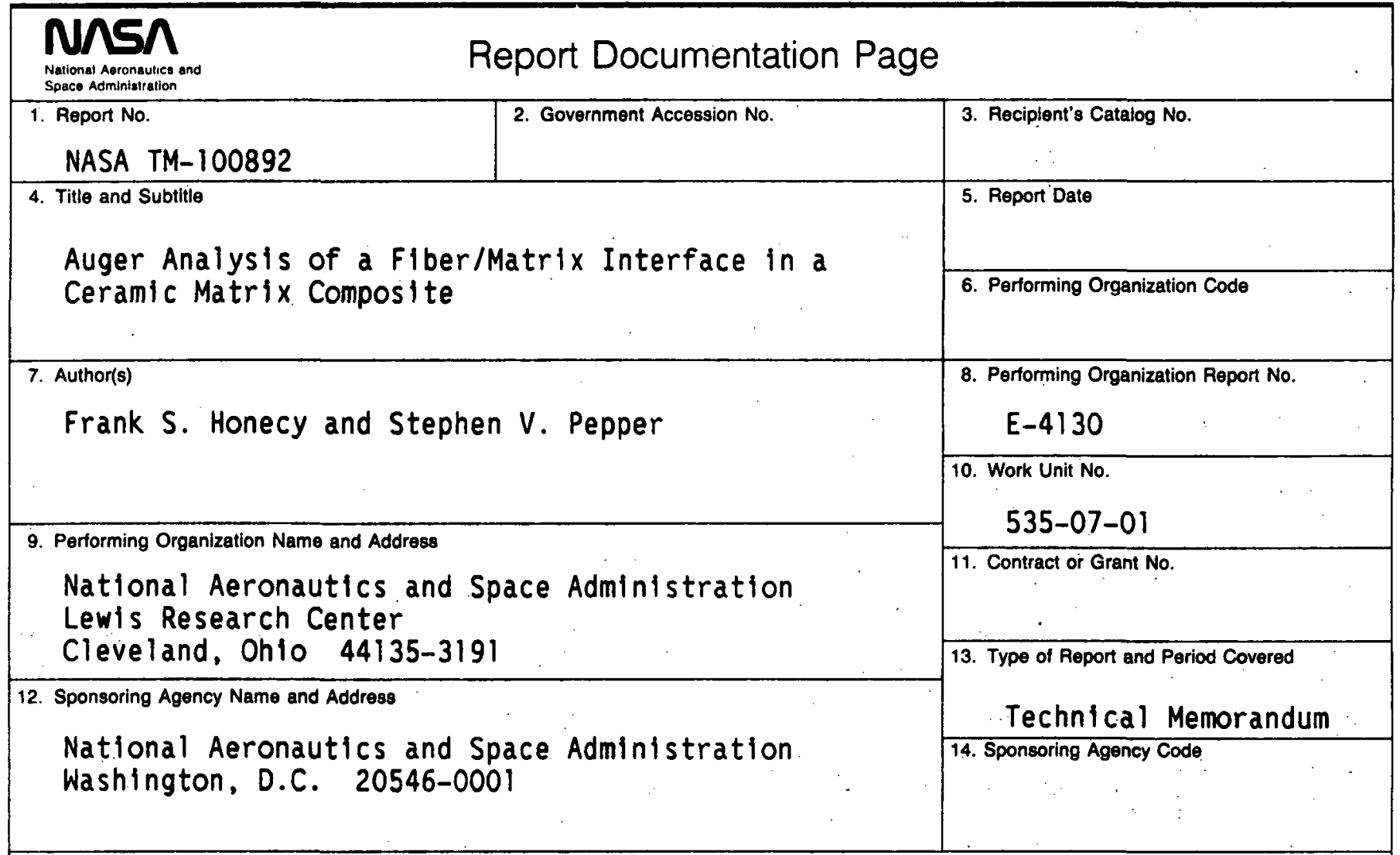

15. Supplementary Notes

Prepared for the Spring Meeting of the Materials Research Soclety, Reno, Nevada, April 4-9, 1988. Frank S. Honecy, Case Western Reserve University, Dept. of Mechanical and Aerospace Englneering, Cleveland, Ohio 44106 and NASA Resident Research Associate; Steven V. Pepper, NASA Lewls Research Center.

16. Abstract

Auger electron spectroscopy (AES) will depth profiling was used to characterize the fiber/matrix interface of a SiC fiber, reaction bonded $\mathrm{Si}_{3} \mathrm{~N}_{4}$ matrix composite. Depth profiles of the "as recelved" double coated fiber revealed concentration osclllations which disappeared after annealing the fiber in the environment used to fabricate the composite. After the composite was fractured, the Auger depth profiles indicated that fallure occurred in neither the B-SiC fiber body nor in the $\mathrm{Si}_{3} \mathrm{~N}_{4}$ matrix but, concurrently, at the fiber coating/matrix interface and within the fiber coating itself.

Ceramic/ceramic composite; Fiber; Matrix; Unclassified - Unilimited AES; Auger electron spectroscopy; Depth Subject Category 24 profiling

\begin{tabular}{|l|l} 
21. No of pages & 22. Price* \\
\hline & $\mathrm{AO2}$
\end{tabular}


National Aeronautics and

Space Administration

Lewis Research Center

Cleveland. Ohio 44135

Orlictal Businoss

Penaly for Pitvato Uso $\$ 500$
SECOND CLASS MAIL

ADDRESS CORRECTION REQUESTED

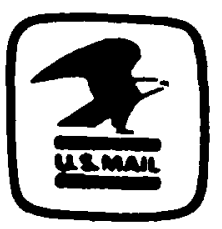

Postage and foes Paid National Aeronautics and Space Administration NASA-451 